\title{
Hepatitis: An emerging presentation in child with coronavirus disease 2019
}

\author{
Viswanathan Varun ${ }^{1}$, Save Sushma ${ }^{2}$, Sawant Vishal ${ }^{3}$, S Kondekar Alpana ${ }^{4}$ \\ From ${ }^{1}$ Speciality Medical Officer, ${ }^{2}$ Professor, ${ }^{3}$ Assistant Professor, ${ }^{4}$ Associate Professor, Department of Pediatrics, Topiwala National Medical College \\ and B.Y.L. Nair Charitable Hospital, Mumbai, Maharashtra, India
}

\begin{abstract}
Severe acute respiratory syndrome coronavirus 2 is an enveloped RNA beta-coronavirus related to the severe acute respiratory syndrome virus and has varied clinical manifestations, commonly involving the respiratory system. Gastrointestinal symptoms with/without respiratory symptoms are increasingly reported. The liver function elevation is usually mild in coronavirus disease 2019 (COVID-19) disease and usually recovers without treatment. However, severe liver injury has been reported in adult studies. Liver injury is emerging as a clinically important consequence of COVID-19. We report a case of a child who presented with fever and acute abdomen in acute liver failure and was tested positive for COVID-19 reverse transcriptase-polymerase chain reaction and was successfully managed without any complications. This rare presentation with acute abdomen should raise the suspicion of COVID-19 and teaches us to develop a broader approach in this evolving pandemic.
\end{abstract}

Key words: Coronavirus disease 2019, Hepatitis, Pediatrics

$\mathrm{S}$ evere acute respiratory syndrome coronavirus 2 (SARS-CoV-2) is an enveloped RNA beta-coronavirus related to the severe acute respiratory syndrome virus which uses the angiotensin-converting enzyme-2 (ACE-2) receptors for cellular entry. The infected person is the main source of infection and the transmission occurs through droplets, fomites followed by airborne [1,2]. The children can be asymptomatic or present with upper respiratory tract symptoms such as nasal congestion, cough, and fever. Some children may present with nausea, vomiting, and abdominal pain. The main target organ is the respiratory system; however, the gastrointestinal tract including hepatobiliary system may also be involved in the form of above symptoms with mild rise in aminotransferases but serious liver dysfunctions are uncommon $[3,4]$.

We report the case of an uncommon manifestation of coronavirus disease 2019 (COVID-19) in the form of severe hepatic derangements as the initial presentation in a child who had a persistent high-grade fever and was tested positive for COVID-19 reverse transcriptase-polymerase chain reaction (RT-PCR), with both parents being COVID-19 positive were referred to our hospital which is designated as dedicated COVID hospital in the ongoing pandemic.

\section{Access this article online}

Received - 31 January 2021

Initial Review - 17 February 2021

Accepted - 12 March 2021

DOI: 10.32677/IJCH.2021.v08.i03.008

\section{CASE REPORT}

A 6-year, 2-month-old boy presented with a history of fever and abdominal pain for 5 days. Fever at onset was moderate grade, intermittent, and progressed to continuous high grade. There was no significant history and had normal birth and development. His weight was $19 \mathrm{~kg}$ (between -1 SD and median) and height was $112 \mathrm{~cm}$ (between -1 SD and median).

On clinical examination, the patient was conscious, oriented, febrile $\left(102^{\circ} \mathrm{F}\right)$ with tachycardia and tachypnea proportionate to fever. $\mathrm{SpO}_{2}$ was $97 \%$ on room air. Blood pressure was 100/64 $\mathrm{mmHg}$ (between $50^{\text {th }}$ and $90^{\text {th }}$ centile). He had icterus over bulbar conjunctiva. Abdominal examination on superficial palpation revealed right hypochondriac tenderness and deep palpation revealed hepatomegaly $(4 \mathrm{~cm})$ below the right costal margin with smooth surface, soft in consistency with round margins and liver span of $10 \mathrm{~cm}$ was found. There were no other signs of liver cell failure and other systemic examination was normal. With significant family history of both parents being diagnosed with COVID-19 infection and high-grade fever, COVID-19 RT-PCR was sent which was positive.

On further investigation, liver function tests (LFTs) revealed serum glutamic-oxaloacetic transaminase (SGOT) of $5046 \quad(15-50 \quad \mathrm{IU} / \mathrm{L})$ and serum glutamic-pyruvic transaminase (SGPT) of 3573 (5-45 IU/L). Total serum bilirubin

\footnotetext{
Correspondence to: Dr. Sushma Save, Department of Pediatrics, $1^{\text {st }}$ Floor College Building, Topiwala National Medical College and B.Y.L. Nair Charitable Hospital, Dr. AL Nair Road, Mumbai Central, Mumbai - 400 008, Maharashtra, India. E-mail: sushmasave73@gmail.com
}

(C) 2021 Creative Commons Attribution-NonCommercial 4.0 International License (CC BY-NC-ND 4.0). 
was $3.9 \mathrm{mg} / \mathrm{dl}$ with direct bilirubin of $2.9 \mathrm{mg} / \mathrm{dl}(<1 \mathrm{mg} / \mathrm{dl})$. Prothrombin time was $34.2 \mathrm{~s}(10-12 \mathrm{~s})$ with control of $13 \mathrm{~s}$ with INR of 2.9. Activated partial thromboplastin time was $53.2 \mathrm{~s}$ (26$36 \mathrm{~s})$ with control of $26 \mathrm{~s}$. Serum albumin was 3.2 (3.5-5.6 g/ dl) and random blood sugar was $83 \mathrm{mg} / \mathrm{dl}$. Renal function tests showed blood urea nitrogen of $4(5-18 \mathrm{mg} / \mathrm{dl})$ and creatinine of $0.6(0.03-0.6 \mathrm{mg} / \mathrm{dl})$. Serum electrolytes showed $\mathrm{Na}^{+}: 139$ (135$145) \mathrm{mEq} / \mathrm{L}$ and $\mathrm{K}^{+}: 4.3(3.3-4.6) \mathrm{mEq} / \mathrm{L}$. Blood gas, urine routine microscopy, serum amylase, and lipase levels were within normal limits. Blood culture was negative. Chest X-ray and standing $\mathrm{X}$-ray abdomen erect were within normal limits.

The patient presented in acute liver failure (ALF) without encephalopathy and was started on hepatic drip (400 $\mathrm{ml} \mathrm{10 \%}$ dextrose $+100 \mathrm{ml} \mathrm{NS}+5 \mathrm{ml} \mathrm{KCL}+5 \mathrm{ml}$ calcium gluconate $+2 \mathrm{ml}$ MVI) and syrup lactulose with injection Vitamin $\mathrm{K}$ and antibiotic, inj. cefotaxime $(150 \mathrm{mg} / \mathrm{kg} /$ day $)$. On further evaluation, viral markers for hepatitis A, B, C, and E, widal titers, rapid diagnostic tests for leptospirosis, malaria, and dengue were negative. HIV, cytomegalovirus, and Epstein-Barr virus DNA PCR were also negative. Abdominal ultrasound revealed hepatosplenomegaly with altered echotexture of liver. Abdominal computed tomography $(\mathrm{CT})$ revealed similar findings with no focal lesion in liver and no dilated portal collaterals.

The child was evaluated for cytokine storm, which revealed erythrocyte sedimentation rate $29 \mathrm{~mm}$ at the end of $1^{\text {st }} \mathrm{h}$ and C-reactive protein (CRP) was $37(0.6-7.9 \mathrm{mg} / \mathrm{L})$. Serum ferritin was $600(7-140 \mathrm{ng} / \mathrm{ml})$ and D-dimers level was $0.9(0.4-2.27 \mathrm{mg} / \mathrm{L})$. Serum lactate dehydrogenase level was $800(150-500 \mathrm{mg} / \mathrm{dl})$.

In view of persistent fever spikes, the patient was also started on syrup azithromycin $(10 \mathrm{mg} / \mathrm{kg} /$ day $)$, Vitamin C, multivitamins, Vitamin D (800 IU/day), and zinc ( $2 \mathrm{mg} / \mathrm{kg} /$ day). The patient was serially monitored for signs of raised intracranial pressure, encephalopathy, bleeding manifestation, hypoglycemia, and electrolyte imbalance in a timely manner and never developed any of these complications. On day 8 of illness, the child had decreased fever spikes with improved appetite, became afebrile by day 11 of illness; however, abdominal pain and hepatic tenderness persisted till day 15 . Laboratory parameters showed recovery as depicted in Table 1. The patient was discharged on day 18 of illness with COVID-19 RT-PCR oropharyngeal swab negative on day 15 of illness. Parents also tested negative for the swab. On follow-up, complete resolution in LFT was observed on day 24 of illness (Graph 1).

\section{DISCUSSION}

The incidence of COVID-19 infections is generally low and associated with a mild course in children. The children have frequent exposure to respiratory syncytial virus, influenza $A$ and influenza B viruses, which enhance their serum antibody levels and could provide cross-protection [5-7]. Furthermore, there are suggestions that ACE enzyme is less mature in children and hence reduced binding of SARS-COV-2 protein [6].

Incidence of gastrointestinal symptoms varies from $12 \%$ to $61 \%$ in patients with COVID-19 [8]. Nausea, vomiting (7\%), anorexia $(21 \%)$, diarrhea $(9 \%)$, and abdominal pain $(3 \%)$ were the most common symptoms [8]. Gastrointestinal symptoms are reported in $15 \%$ of patients with COVID-19 and liver injury in $19 \%$ of patients [9]. Liver injury, as manifested by SGPT and SGOT elevation more than 3 times the upper limit of normal, is emerging as a clinically important consequence of COVID-19. The prevalence of liver injury was $15.7 \%$ as observed by Ahmed et al. Liver injuries in these patients have multiple mechanisms. Liver expresses ACE-2 receptors selectively on cholangiocytes.

SARS-CoV2 uses the ACE receptors for cell entry which suggests a direct toxic effect of the virus leading to bile duct epithelial cell injury. The virus activates toll receptors and autoreactive $\mathrm{T}$ cells leading to cellular apoptosis and necrosis and release of pro-inflammatory cytokines leading to cytokine storm characterized by elevated levels of inflammatory markers such as ferritin and CRP [10]. Sepsis in COVID-19 leads to hypoxic ischemic damage to liver leading to altered liver enzymes resulting in higher morbidity and longer duration of intensive care unit stay $[10,11]$. Our patient had abdominal pain and high-grade fever with strong family history of both parents being COVID-19 positive and elevation of transaminases leading to the suspicion of COVID hepatitis.

Management of such patients requires good supportive management that involves hydration, prevention of hypoglycemia; avoids electrolyte disturbances to minimize ischemic damage to liver. Good antibiotic cover should be provided to minimize sepsis and reduce the complications of cytokine storm. In events of acute deterioration of hepatic encephalopathy, care should be taken regarding the management of raised intracranial pressure and the prevention of sepsis.

To rule out infective, autoimmune, and metabolic causes of liver failure, a detailed evaluation has to be carried out. The

Table 1: Serial laboratory investigation

\begin{tabular}{|c|c|c|c|c|c|c|}
\hline Day of illness & CBC (Hb/TLC/PIt/N: L ratio) & SGOT & SGPT & Bilirubin (T/D) & CRP & PT/INR \\
\hline 8 & $12.3 / 4300 / 115,000 / 6: 1$ & 5046 & 3573 & $3.9 / 2.9$ & 37 & $34.2 / 2.9$ \\
\hline 10 & $9.7 / 13.400 / 207,000 / 4: 1$ & 1707 & 2717 & $2.8 / 1.1$ & 25 & $22.3 / 1.8$ \\
\hline 13 & $10.9 / 15,800 / 275,000 / 3: 1$ & 263 & 500 & $2.5 / 0.9$ & 12 & $18 / 1.7$ \\
\hline 18 & $10.2 / 15,200 / 300,000 / 2: 1$ & 89 & 250 & 0.7 & 5 & $15.6 / 1.1$ \\
\hline 21 & $10.1 / 8500 / 320,000 / 2: 1$ & 55 & 130 & 0.5 & & \\
\hline 24 & $10.1 / 7800 / 320,000 / 2: 1$ & 45 & 50 & 0.4 & & \\
\hline 3 months & $10.2 / 6500 / 370,000 / 2: 1$ & 24 & 34 & 0.3 & & $14 / 1.0$ \\
\hline
\end{tabular}

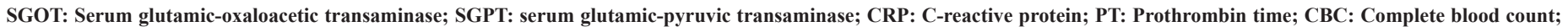

Hb: Hemoglobin; TLC: Total leukocyte count 


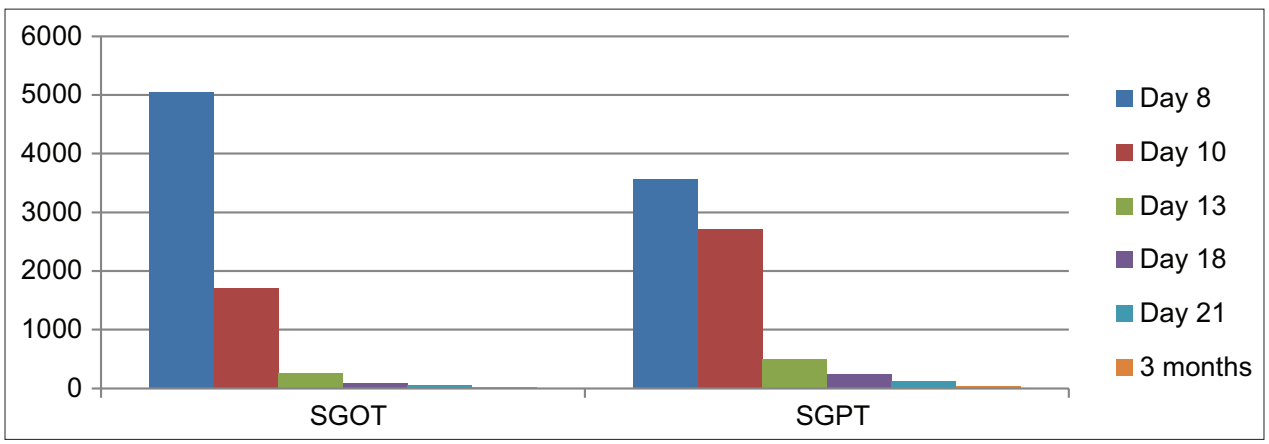

Graph 1: Serum glutamic-oxaloacetic transaminase and serum glutamic-pyruvic transaminase trends

patient showed early signs of recovery with improvement of clinical symptoms and repeat follow-up at 3 months showed normal liver profile, hence, autoimmune workup and $24 \mathrm{~h}$ urine copper were not carried out. Radiological investigations such as abdominal ultrasound, portal Doppler, and CT abdomen did not signify any positive finding. Liver biopsy was not considered as the child had early signs of recovery.

SGPT levels correlate well with markers of inflammation and are likely higher among patients with severe cytokine release syndromes in adults [12]. It is possible that younger patients mount a more robust immune and inflammatory response to infection, and that higher peak SGPT is a manifestation of it [12]. Role of immunomodulators like tocilizumab in cases of ALF in COVID-19 patients has been investigated with adult patients showing improvement but its role in pediatric patients should be investigated [13].

Similar case report of ALF associated with COVID-19 was seen in an 11-year-old by Saeed et al. who presented with similar complaints and strong family history of both parents being COVID-19 RT-PCR positive but deteriorated with hepatic encephalopathy and expired [14]. The patient was followed up, and after 3 months, there were no episodes of reactivation and deranged LFT.

\section{CONCLUSION}

This case report shows the variability in the presentation of COVID-19 and also emphasizes that gastrointestinal manifestations should raise the suspicion of SARS-COV-2. Any patient with hepatitis should be investigated for COVID-19 even in the absence of respiratory symptoms for early diagnosis and management. COVID-19-positive patients are at risk of liver injury and detailed evaluation should be practiced for better understanding of the course of the disease and causal association. LFT may further help us in predicting cytokine storm and help in timely management and improved patient care and reduced morbidity. Further studies are required on a larger scale to determine the frequency and severity of this presentation, along with the morbidity and mortality profile during this evolving pandemic.

\section{REFERENCES}

1. Ravikumar N, Nallasamy K, Bansal A, Angurana SK, Basavaraja GV, Sundaram M, et al. Novel coronavirus 2019 (2019-nCoV) infection: Part I-preparedness and management in the pediatric intensive care unit in resource-limited settings. Indian Pediatr 2020;57:324-34.

2. Government of India. Clinical Management Protocol: COVID-19. New Delhi: Government of India; 2020.

3. Matthai J, Shanmugam N, Sobhan P, Indian Society Of Pediatric Gastroenterology, Hepatology and Nutrition; Pediatric Gastroenterology Chapter of Indian Academy of Pediatrics. Coronavirus disease (COVID-19) and the gastrointestinal system in children. Indian Pediatr 2020;57:533-5.

4. Zhang C, Shi L, Wang FS. Liver injury in COVID-19: Management and challenges. Lancet Gastroenterol Hepatol 2020;5:428-30.

5. Mustafa NM, Selim LA. Characterisation of COVID-19 pandemic in paediatric age group: A systematic review and meta-analysis. J Clin Virol 2020;128:104395.

6. Ludvigsson JF. Systematic review of COVID-19 in children shows milder cases and a better prognosis than adults. Acta Paediatr 2020;109:1088-95.

7. Balasubramanian S, Rao NM, Goenka A, Roderick M, Ramanan AV. Coronavirus disease 2019 (COVID-19) in children-what we know so far and what we do not. Indian Pediatr 2020;57:435-42.

8. Gupta A, Madhavan MV, Sehgal K, Nair N, Mahajan S, Sehrawat TS, et al. Extrapulmonary manifestations of COVID-19. Nat Med 2020;26:1017-32.

9. Mao R, Qiu Y, He JS, Tan JY, Li XH, Liang J, et al. Manifestations and prognosis of gastrointestinal and liver involvement in patients with COVID-19: A systematic review and meta-analysis. Lancet Gastroenterol Hepatol 2020;5:667-78.

10. Luglio M, Tannuri U, de Carvalho WB, Bastos KL, Rodriguez IS, Johnston C, et al. COVID-19 and liver damage: Narrative review and proposed clinical protocol for critically ill pediatric patients. Clinics (Sao Paulo) 2020;75:e2250.

11. Ahmed J, Rizwan T, Malik F, Akhter R, Malik M, Ahmad J, et al. COVID-19 and liver injury: A systematic review and meta-analysis. Cureus 2020;12:e9424.

12. Phipps MM, Barraza LH, LaSota ED, Sobieszczyk ME, Pereira MR, Zheng EX, et al. Acute liver injury in COVID-19: Prevalence and association with clinical outcomes in a large U.S. cohort. Hepatology 2020;72:807-17.

13. Serviddio G, Villani R, Stallone G, Scioscia G, Foschino-Barbaro MP, Lacedonia D. Tocilizumab and liver injury in patients with COVID-19. Therap Adv Gastroenterol 2020;13:175628482095918.

14. Saeed A, Shorafa E, Shahramian I, Afshari M, Salahifard M, Parooie F. An 11-year-old boy infected with COVID-19 with presentation of acute liver failure. Hepat Mon 2020;20:e104415.

Funding: None; Conflicts of Interest: None Stated.

How to cite this article: Varun V, Sushma S, Vishal S, Alpana SK. Hepatitis: An emerging presentation in child with coronavirus disease 2019. Indian J Child Health. 2021; 8(3):139-141. 